4-8-2019

\title{
Why and when witnessing uncivil behavior leads observers to punish frontline employees and leave the firm
}

Ismail Karabas

Murray State University, ikarabas@murraystate.edu

Jeff Joireman

Washington State University, joireman@wsu.edu

Shinhye Kim

University of Missouri - Columbia, kimshin@missouri.edu

Follow this and additional works at: https://digitalcommons.murraystate.edu/faculty

Part of the Hospitality Administration and Management Commons

\section{Recommended Citation}

This is an Accepted Manuscript of an article published by Elsevier in International Journal of Hospitality Management (Volume 82) on April 8, 2019, available online: https://doi.org/10.1016/j.ijhm.2019.03.019

This Peer Reviewed/Refereed Publication is brought to you for free and open access by Murray State's Digital Commons. It has been accepted for inclusion in Faculty \& Staff Research and Creative Activity by an authorized administrator of Murray State's Digital Commons. For more information, please contact msu.digitalcommons@murraystate.edu. 
Status of Paper: In press, International Journal of Hospitality Management

\title{
Why and When Witnessing Uncivil Behavior
}

\section{Leads Observers to Punish Frontline Employees and Leave the Firm}

\author{
Ismail Karabas \\ Department of Management, Marketing, and Business Administration \\ Murray State University \\ Murray, KY 42071 \\ ikarabas@murraystate.edu \\ Jeff Joireman \\ Department of Marketing \\ Washington State University \\ Box 644730 \\ Pullman, WA 99164-4730 \\ 509-335-0191, joireman@wsu.edu \\ ShinHye Kim \\ Department of Marketing \\ Trulaske College of Business \\ University of Missouri \\ Columbia, MO, 65211 \\ kimshin@missouri.edu
}




\begin{abstract}
The present studies examined observer responses to failed recoveries following a service failure in a restaurant setting. Study 1 demonstrated that, relative to a neutral response, a negative server response increased desire for revenge and negative firm attitudes, which reduce tipping and return intentions, but revealed no benefits of a positive server response. Study 2 highlighted the full buffering effect of management apology on firm-related outcomes (attitudes, return intentions) which did not extend to employee-related outcomes (desire for revenge, tipping). Study 2 also supported a structural model in which negative server responses generate perceived deontic injustice, which predicts desire for revenge and firm attitudes, which in turn predict tipping and return intentions. By including outcomes more directly reflecting “revenge seeking” (tipping), and testing the most comprehensive structural model to date, the present work contributes to a fuller understanding of how customers respond to observed service failures.
\end{abstract}




\section{Introduction}

Whether dining out, shopping in a mall, or waiting to check in for a flight, customers often observe uncivil behavior (i.e., "insensitive, disrespectful, or rude behavior directed at another person that displays a lack of regard for that person”; Porath, MacInnis, and Folkes 2010; p. 292). Indeed, across restaurant, retail, and airline sectors, $62 \%$ of those surveyed observed employees mistreating other employees, while 56\% witnessed employees treating other customers poorly (Porath, MacInnis, and Folkes 2011). Given their ubiquity, an important question for hospitality managers and researchers is how, why, and when observing uncivil behaviors influences customers. Notably, a growing number of studies reveal that observed incivilities lead to anger, reduced satisfaction, reluctance to return to and recommend a service provider, and a desire to "get even” with the offending party (e.g., Casidy and Shin 2015; Mattila, Hanks, and Wang 2014; Melián-González and Bulchand-Gidumal 2017; Porath et al. 2010, 2011; Van Vaerenbergh, Vermeir, and Larivière 2013; Wan, Chan, and Su 2011).

Building on these studies, the present work examines how third party observers respond when they witness another customer experience a service failure followed by a failed (versus successful) recovery. While extant research offers useful insights into this phenomenon, as we detail in our review of the literature, important questions remain. We address these questions by (a) integrating outcomes that more directly reflect "revenge” behaviors (i.e., tipping); (b) clearly separating the actions of frontline employees (responsible for the failed recovery) and management (as a source of intervention following the failed recovery); and (c) developing and testing an integrative model to explain responses to observed service failures and failed recoveries (using structural equation modeling). 


\section{Literature Review}

\subsection{Social-Servicescape}

Services are often delivered in public spaces. Recognizing the importance of this socialservicescape (Hanks and Line 2018; Tombs and McColl-Kennedy 2003), researchers have devoted increasing attention to how customers are affected by interactions among others in service settings (e.g., Miao 2014; Miao et al. 2011). To help organize this space, Figure 1 depicts interactions a focal customer may encounter in the social-servicescape; black lines represent the current studies' focus. A focal customer may interact with their own service provider (path a), interact with or observe adjacent customers (path b), or observe an interaction between service employees (path c), between a different service employee and an adjacent customer (path d), or between their own service provider and another customer (path e). The focal customer may also observe a manager interact with a service employee (path f) or an adjacent customer (path g). Understandably, much hospitality and service research has focused on direct interactions between customers and service providers (path a) (e.g., Chang 2016; Kwon and Jang 2012; Smith and Bolton 1998; Wu and Mattila 2013). As we explain, more recent research examines the impact of observing others' interactions in the social-servicescape.

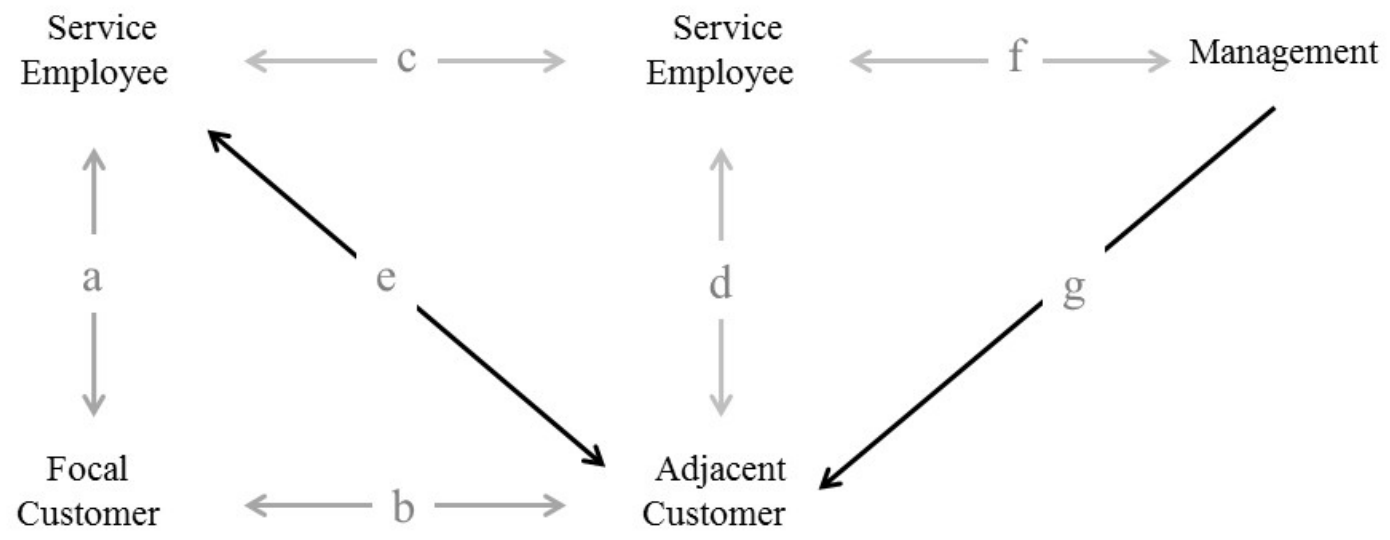

Figure 1 - Direct and observed interactions in the social-servicescape 


\subsection{Directly-Experienced Service Failures and Failed Recoveries (Path A)}

Hospitality providers strive to offer a friendly and welcoming environment. Still, service failures and failed recoveries are nearly unavoidable (Tax, Brown, and Chandrashekaran 1999). Service failures occur when service does not meet a customer's expectations (Bell and Zemke 1987), and service failures can sometimes be followed by failed recoveries (i.e., double deviation; Bitner, Booms, and Tetreault 1990). For example, after a hotel patron complains about a lack of warm water in her room (service failure), a service employee may treat the customer rudely (failed recovery). Service failures and failed recoveries can occur as process failures (e.g., slow service) or outcome failures (e.g., wrong order) (Smith, Bolton, and Wagner 1999), and often involve uncivil (rude, insensitive) employee actions (Porath et al. 2011).

Directly experienced service failures, failed service recoveries, and uncivil employee actions are problematic because they lead to dissatisfaction (McCollough, Berry, and Yadav 2000), anger (McColl-Kennedy, Patterson, Smith, and Brady 2009), negative word of mouth (Richins 1983), switching brands (Singh 1990), sabotaging (Kähr, Nyffenegger, Krohmer, and Hoyer 2016), and loss of market share (Keiningham et al. 2014). One mechanism explaining these negative reactions is perceived injustice (Joireman, Grégoire, Devezer, and Tripp 2013), which can manifest as distributive injustice (unfair outcomes), procedural injustice (unfair processes), or interactional injustice (unfair treatment). Perceived injustice, in turn, is a more proximal predictor of customer reactions, namely, a desire for revenge against the offending party (Bechwati and Morrin 2003; Grégoire, Tripp, and Legoux 2009; Joireman et al. 2013).

\subsection{Observed Service Failures, Failed Recoveries, and Incivilities}

Customers can also witness incivilities and injustices occurring between other actors in service settings. While customers show stronger negative responses to directly experienced (vs. 
observed) service failures (e.g., Casidy and Shin 2015) and incivilities (Porath et al. 2011), a growing number of studies suggest that observed service failures and incivilities lead to negative observer reactions, with some studies suggesting observers desire to "get revenge" on the perpetrator, despite having no personal stake in the matter.

Several studies have focused on observed interactions among employees (path c) or between employees and managers/employers (path f). For example, Porath et al. (2010) show that customers who observe uncivil employee interactions report greater anger, rumination, and negative generalizations about other employees who work for the firm. In another paper, Porath et al. (2011, Studies 2-3) find that customers who imagine a manager treating an employee in an uncivil manner show lower future purchase intentions, higher levels of anger, perceived injustice, negative word of mouth, and desire to get revenge against the manager. Similarly, Melián-González and Bulchand-Gidumal (2017) show that hotel visitors have lower perceived justice, attitudes, satisfaction, return intentions, and positive word of mouth after imagining online reviews describing an employer's negative or ambivalent treatment of employees.

Additional studies have examined reactions to overheard service failures and failed recoveries involving interactions between either adjacent customers/frontline employees (path e) or adjacent customers/managers (path g). For example, across two studies, Van Vaerenbergh et al. (2013) find that customers who observe frontline employees treat a complaining customer in an uncivil manner report lower satisfaction, perceived service quality, and return intentions, with stronger effects when the customer is not to blame for the failure. More recently, Mattila et al. (2014) show that observers who witness a manager respond in an uncivil manner to a complaining customer report greater anger and negative word of mouth, and lower perceived justice, return intentions, and positive word of mouth, effects which were stronger when 
observers adopted an experiential (vs. rational) processing frame. Finally, Wan et al. (2011) find that observers of others' service failures are more likely to blame the service provider and have lower satisfaction if the victim is similar (vs. dissimilar) to the observer.

\section{$2.4 \quad$ Mediators}

Many of the studies just reviewed have also tested for mechanisms linking observation of incivilities with distal outcomes. For example, using Sobel (1982) tests of indirect effects, Porath et al. (2010) found evidence that observed incivility (between employees) leads to anger, rumination, and finally, negative generalizations about others who work for a firm, while Porath et al. (2011, Study 3) reported that observed incivility (between a manager and an employee) led to perceived injustice, which then predicted return intentions and negative word of mouth. Mattila et al.'s (2014) multiple regression analyses, in turn, suggest that perceived injustice mediates between observing an uncivil manager/customer interaction and future purchase intentions (full mediation) and negative word of mouth (partial mediation). Finally, using Hayes' PROCESS program, Henkel and colleagues (2017) find that customers who observe another customer treat an employee in an uncivil manner report higher warmth for the server which in turn predicts desire to show support for the server (e.g., to cheer up the server).

\subsection{Open Questions}

In sum, prior studies offer insight into how customers respond when they witness service failures, failed recoveries, and incivilities. Despite this, important questions remain. First, studies on overheard service failures and observed incivilities have focused on a range of reactions thought to reflect "revenge seeking” including desire for revenge, reduced purchase intentions, and negative word of mouth. While relevant, Porath et al. (2011, p. 5) note that such outcomes are "not perfect measures of revenge seeking," but rather, proxies for revenge seeking. To 
address this issue, we incorporate outcomes directly reflecting revenge behavior, namely, an observer's inclination to tip a server involved in a failed vs. successful recovery.

Second, while prior research has examined how observers respond to the actions of frontline employees (Van Vaerenbergh et al. 2013) or managers (Mattila et al. 2014) involved in failed recoveries, no study has simultaneously explored whether an intervention (by management) can buffer negative responses to witnessing failed recoveries (by frontline employees). We address this gap by testing how a manager's apology (to the victim of a failed recovery by the frontline employee) affects observers' responses to the firm (attitudes, return intentions) and frontline employee (desire for revenge, tip percentage).

Finally, while studies have identified mechanisms explaining observers’ responses to failed recoveries, the focus has been on a limited number of specific mediators such as perceived injustice (Mattila et al. 2014) and customer satisfaction (Van Vaerenbergh et al. 2013). Moreover, research has relied on multiple regression, the Sobel (1982) test, or indirect effects testing (i.e., using Hayes 2018). The present studies extend this work by developing and testing using structural equation modeling (SEM) - an overarching theoretical model integrating perceptions of deontic injustice (i.e., perceived injustice inflicted on a third party; Skarlicki, O’Reilly, and Kulik 2015), attitude toward the firm, and desire for revenge (i.e., customers' need to punish and cause harm to [an agent] for the damages they have caused; Grégoire et al. 2009).

Development and testing of broad theoretical models (e.g., via SEM) offers coherence to a field by integrating theoretically-relevant constructs which may be scattered throughout the literature. This offers insight into how the constructs are interrelated and work as a whole, shedding deeper insight into how a relevant process unfolds (beyond indirect effects). Bagozzi and Yi (2012, p. 12) explain that SEM can be used to facilitate understanding "as a holistic 
process for discerning meaning from any research enterprise.” And, comparing SEM to mediation testing, Iacobucci (2009, p. 673) argues: "If mediation clarifies the conceptual picture somewhat, with the insertion of just one new construct— the mediator-imagine how much richer the theorizing might be if researchers tried to formulate and test even more complex nomological networks" (i.e., theoretical models).

To address these issues, we develop and test an integrative conceptual model (Figure 2). Study 1 examines how the valence of a server's response (positive vs. negative vs. neutral) influences responses toward the firm and server while offering a preliminary test of the model (without management intervention or deontic injustice). Study 2 examines the buffering effect of management intervention on the downstream outcomes and provides a test of the entire model.

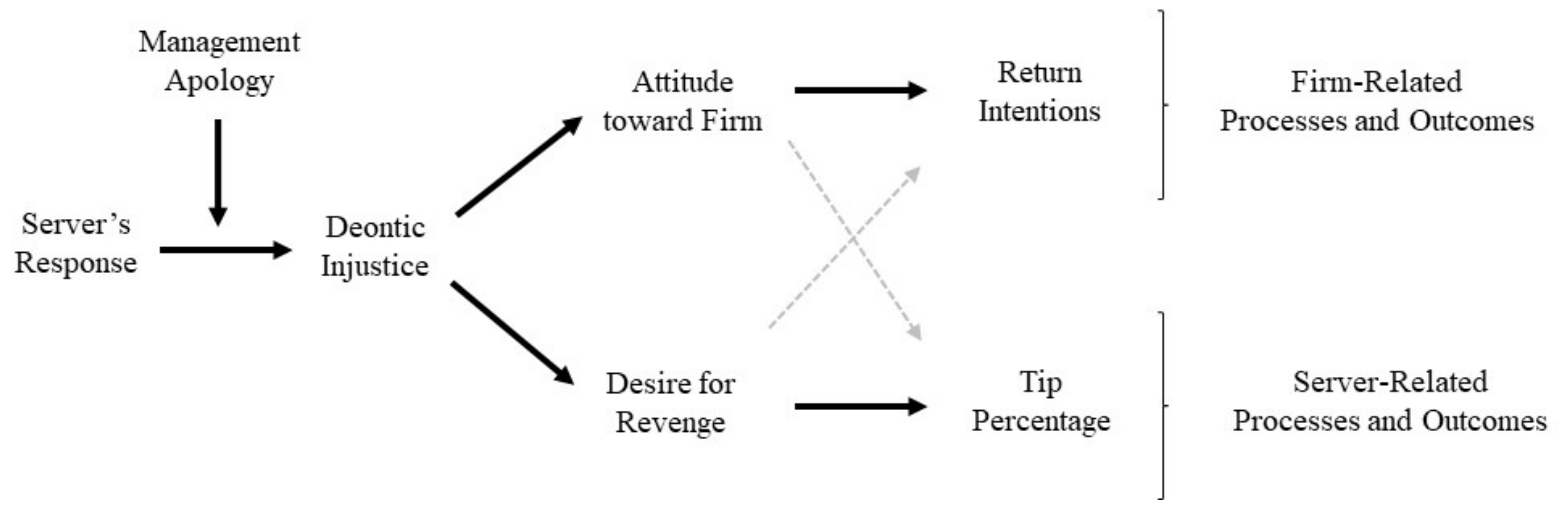

Figure 2 - Conceptual Model

\section{Conceptual Development and Hypotheses}

\subsection{Mediation Model}

As erstwhile reviewed, previous research shows that observers respond unfavorably when they witness a failed recovery. It is less clear why this occurs. Our model (Figure 2) assumes that when observers witness other customers being treated badly, it will drive perceptions of deontic 
injustice, or a sense that a third party has been treated unfairly (Skarlicki et al. 2015). Perceived deontic injustice, in turn, should result in unfavorable treatment of the firm and employee, for two reasons. First, perceptions of deontic injustice should lead to negative attitudes toward the firm, given that observers of overheard service failures often generalize their negative impressions to other employees in the firm (Porath et al. 2010). Second, perceived deontic injustice is likely to engender a desire for revenge against the offending party (Mattila et al. 2014; Porath et al. 2011). Consistent with this reasoning, third party observers have been found to punish norm violators (Lin, Dahl, and Argo 2013), even when not directly affected by the norm violation (Fehr and Fischbacher 2004). Moreover, recent work on third party observers of service failures suggests deontic injustice mediates the effect of a negative server response on desire for revenge, return intentions, and word of mouth (Mattila et al. 2014; Porath et al. 2011). However, previous research has not tested whether desire for revenge mediates between perceptions of deontic injustice and distal outcomes. Given the importance deontic injustice theory accords to “revenge seeking motives” (Mattila et al. 2014; Porath et al. 2011), testing desire for revenge as a mediating mechanism (e.g., perceived deontic injustice $\rightarrow$ desire for revenge $\rightarrow$ tipping) is warranted. In addition, to establish the independent role of the attitude and the revenge mechanisms, it is important to test the extent to which both mechanisms (attitudes toward the firm and desire for revenge) drive distal outcome variables for the firm and server. This reasoning led us to test a set of four hypotheses embedded in our model:

H1: When servers respond negatively to an adjacent customer’s complaint, third party observers will form less favorable attitudes toward the establishment (H1a) and will be less likely to return to the establishment (H1b). 
H2: Perceived deontic injustice and attitude toward the restaurant will (in that order) mediate the effect of the server's response on return intentions.

H3: When servers respond negatively to an adjacent customer's complaint, third party observers will have a stronger desire for revenge against the server (H3a) and will give the server a lower tip (H3b).

H4: Perceived deontic injustice and desire for revenge against the server will (in that order) mediate the effect of the server's response on tip percentage.

\subsection{Moderating Role of Management Intervention (Apology)}

When service failures occur, service providers often interven, for example, by offering an apology. Many studies support the efficacy of apologies in reducing negative customer responses to service failures (Joireman et al. 2013; McCollough et al. 2000; Smith et al. 1999; Wirtz and Mattila 2004). The target of these apologies, however, has typically been the complaining customer. Two recent exceptions find that third party observers form more favorable attitudes and behavioral intentions toward a firm after the frontline employee or the manager apologize to another complaining customer (Mattila et al. 2014; Van Vaerenberg et al. 2013). However, as noted earlier, no studies on overheard service failures have separated the response of the frontline employee from the response of the manager. We explore this issue in study 2, where observers overhear a frontline employee respond negatively (vs. neutrally) to a complaining customer while a manager either apologizes (or does not apologize) to the complaining customer.

Based on the preceding studies (Mattila et al. 2014; Van Vaerenberg et al. 2013), we posited that management intervention (apology) should have a buffering effect on firm-related outcomes (i.e., attitude toward the restaurant and return intentions). Whether apologies also reduce third parties' negative responses toward a server is an open question. On the one hand, 
management apology may lead to a positive "halo effect" which results in less negative responses to the server. On the other hand, observers may distinguish between the "one bad apple” (offending employee) and other employees in the firm. If true, observers would continue to punish the employee while avoiding (or reducing) negative generalizations to the establishment as a whole. Given these competing perspectives, we treated this as an open research question (RQ). Thus, we only advanced hypotheses concerning firm-related outcomes. H5: Management intervention will moderate the impact of server's response, such that the effect of a negative server's response on attitude toward the restaurant (H5a) and return intentions (H5b) will be attenuated when management apologizes (vs. no apology).

H6: Deontic injustice and attitude toward the restaurant will (in that order) mediate the interaction between servers' response and management apology on return intentions. RQ: Will management intervention moderate the impact of server's response on desire for revenge against the server and tip percentage?

\section{Study 1}

\section{1. $\quad$ Method}

\subsubsection{Sampling and Participants Profile}

A convenience sample of 423 undergraduate business students participated in study 1 (42.1\% female; median age $=21 ; 72.3 \%$ Caucasian; detailed sample demographics shown in Web Appendix A). Participants were incentivized through course credit and entrance into a drawing for a \$25 Amazon gift card. Procedures for both studies were reviewed by the authors' institutional review board and deemed low risk and exempt from review.

\subsubsection{Scenario Development}

As prior research indicated overheard service failures often occur in restaurants (Porath et al. 2010), we used a restaurant context. A scenario method was selected following past research 
on service failures, where this method has been theoretically justified (Bitner 1990; Smith and Bolton 1998) and is commonly used (e.g., Bolton and Mattila 2015; McCollough et al. 2000).

We aimed to develop a brief yet detailed scenario that participants could relate to and was not at either end of an extreme on price. Thus, we positioned the restaurant as a "reasonably priced restaurant that was cool but not too fancy.” We also explained that participants were eating with a friend and that the overheard complaining customer was with a friend. As our goal was to manipulate the interaction between the complaining customer and server, and not the observer's service experience, we explained that the participant (i.e., observer) was enjoying their meal with their friend (no service failure).

Once the core restaurant scenario was explained, participants were randomly assigned to one of nine different scenarios based on a 3 (server's response: negative, neutral, positive) x 3 (complaint severity: low, high, high-repeated) between-subjects design. Participants first read about the customer's complaint, followed by the server's response. For the complaint severity conditions, we included three conditions. In the low complaint severity condition, the customer at the next table politely informs the server that his/her food is 20 minutes late. In the high complaint severity condition, the customer complains that it is "taking forever," uses an expletive, and yells in a loud voice. In the high complaint severity repeated condition, the customer makes the same high level complaint and then, after the server responds, the complaining customer again swears, and says he/she is never coming back.

We also incorporated three server response conditions. In the positive server response condition, the server apologizes and promises to fix the problem immediately. In the negative server response condition, the server does not apologize and treats the customer rudely. In a neutral server response condition, the server does not apologize, but does promise to fix the 
problem. We incorporated a neutral (control) condition to determine the nature of the difference between the positive and negative server response conditions (i.e., whether positive server responses enhance favorable observer responses, negative server responses reduce favorable observer responses, or both). More details on the scenarios appear in Web Appendix B.

\subsubsection{Measures}

After reading the scenario, participants completed a six-item attitude toward the restaurant scale (Sawyer and Howard $1991 ; \alpha=.95$ ), rated their likelihood of returning to the restaurant ( 1 = very unlikely, 7 = very likely), completed a desire for revenge toward the server scale (Grégoire et al. 2009; $\alpha=.95)$, and indicated their tip percentage using a slider scale (0\% 25\%) (Lynn and McCall 2000; Voorhees, Brady, and Horowitz 2006) (scale items appear in Web Appendix C). ${ }^{1}$ To avoid drawing attention to our manipulations, we conducted separate manipulation check studies, as described in the results section.

Measurement analyses supported the discriminant and convergent validity of the two multiple-item scales (attitudes and desire for revenge): Confirmatory factor analysis indicated a two-factor model fit better than a one-factor model: $\chi 2(1)=62.56, p<.001$; the square root of the average variance extracted (AVE) for each construct $(.87, .83)$ exceeded the correlation between the constructs (-.37) (Fornell and Larcker 1981); the composite reliability of each scale exceeded $.70(.94, .93)$; and the AVE for each construct exceeded $.50(.76, .70)$. That said, to achieve a completely satisfactory CFA model fit, it was necessary to estimate one correlation between error terms on the desire for revenge scale and three correlations between error terms on

\footnotetext{
${ }^{1}$ Participants also indicated the likelihood they would recommend the restaurant and tip the server. Analysis on recommending and tip likelihood paralleled results reported for return intentions and tip percentage. A complete summary is available from the first author.
} 
the attitude toward the restaurant scale. With these correlated errors estimated, the measurement model fit the data well, $\chi 2(39)=60.58, p<.05, \mathrm{CFI}=.99, \mathrm{TLI}=.99$, and $\mathrm{RMSEA}=.037$.

\subsection{Results}

\subsubsection{Manipulation Checks}

To test the server response manipulation, 92 participants from MTurk, not run in the main study, imagined a customer at an adjacent table complaining over slow service, and rated one of three server responses (negative, neutral, or positive) on a six-item impressions scale (Web Appendix $C ; \alpha=.95)$. One-way ANOVA yielded a significant effect of server response, $F(2,89)$ $=31.67, p<.001$. As expected, participants had an unfavorable impression of the server in the negative server response condition $(M=2.89$; below the midpoint of $4, p<.05)$ and a favorable impression of the server in the positive server response condition $(M=5.36$; above $4, p<.001)$, with impressions in the neutral response condition falling in the middle $(M=3.74$; not different than $4, p=.24)$. Tukey tests revealed significant differences between all means $(p<.05)$.

To test the customer complaint manipulation, 91 additional participants from MTurk, not run in the primary study, imagined they overheard a customer at an adjacent table making one of the three complaints used in our primary study (low, high, or high-repeated) and were told "the server provided the complaining customer with a response.” Participants then rated the customer's complaint on the six-item scale just noted $(\alpha=.95)$. One-way ANOVA revealed a significant effect of customer complaint, $F(2,88)=46.39, p<.001$. As expected, participants had an unfavorable impression of the customer in the high severity $(M=2.11$; below the midpoint of $4, p<.001)$ and high severity repeat conditions $(M=2.17$; below $4, p<.001)$, and somewhat positive impressions of the customer in the low severity complaint condition $(M=$ 4.75; above $4, p<.001)$. Tukey tests indicated that each of the high severity conditions differed 
from the low severity condition $(p<.05)$, but the two high severity conditions did not differ.

Nevertheless, we included the high severity complaint repeat condition for exploratory purposes.

\subsubsection{Firm-Related Outcomes}

To test $\mathrm{H}_{1}$, we conducted 3 (server’s response: negative vs. neutral vs. positive) x 3 (complaint severity: low vs high vs. high-repeated) ANOVAs on attitude toward the restaurant and return intentions. Results revealed a significant server response main effect on each of the outcome measures $(p<.001)$, but no main or interactive effects $(p$-values $>.20)$ for customer complaint severity (means appear in Table 1). Tukey tests showed that attitude toward the restaurant and return intentions were significantly lower in the negative server response condition (vs. neutral and positive conditions) $(p<.05)$, supporting $\mathrm{H}_{1}$.

\subsubsection{Server-Related Outcomes}

To test $\mathrm{H}_{3}$, we conducted 3 (server's response: negative vs. neutral vs. positive) x 3 (complaint severity: low vs high vs. high-repeated) ANOVAs on desire for revenge against the server $^{2}$ and tip percentage. Results revealed a significant main effect of server's response on both dependent measures (Table 1). Supporting $\mathrm{H}_{3}$, Tukey post hoc tests revealed that desire for revenge was significantly higher and tip percentage was significantly lower, in the negative server response condition than in the neutral and positive server response conditions $(p<.05){ }^{3}$

\footnotetext{
${ }^{2}$ There were four outliers in study 1 and two outliers in study 2 within desire for revenge (z-scores > 3.29). Since removing the outliers did not alter the results, we used the complete datasets for each study. ${ }^{3}$ While there was no main effect for customer complaint ( $p$-values $\left.>.61\right)$, results also revealed a server response x complaint severity interaction on desire for revenge, $F(4,401)=2.83, p<.05$. However, because this interaction was not replicated in study 2, we do not discuss it in detail. Details can be obtained from the first author.
} 


\section{Server's Response}

\begin{tabular}{|c|c|c|c|c|}
\hline Outcomes & Negative & Neutral & Positive & Univariate $\mathrm{F}$ \\
\hline \multicolumn{5}{|l|}{ Firm-Related } \\
\hline Attitude toward Restaurant & $3.44 a$ & $4.55 b$ & $4.78_{b}$ & $58.12 * * *$ \\
\hline Return Intentions & $3.91_{\mathrm{a}}$ & $4.70_{b}$ & $4.86 \mathrm{~b}$ & $19.10^{* * *}$ \\
\hline \multicolumn{5}{|l|}{ Server-Related } \\
\hline Desire for Revenge & $2.07 \mathrm{a}$ & $1.70_{\mathrm{b}}$ & $1.68 \mathrm{~b}$ & $4.94 * *$ \\
\hline Tip Percentage & $9.87 \mathrm{a}$ & $12.06 \mathrm{~b}$ & $12.02 \mathrm{~b}$ & $6.95 * * *$ \\
\hline
\end{tabular}

Note: Means in a row not sharing a subscript differ significantly according to Tukey tests $(p<.05)$. Server-related outcomes $(N=410)$; firm-related outcomes $(N=421)$.

\section{Table 1 - Main Effect of Server's Response (Study 1)}

\subsubsection{Structural Equation Models}

We next used SEM to test the model linking server's response to return intentions and tip percentage and through attitude toward the restaurant and desire for revenge. Given the Tukey test results, we partitioned server's response into two orthogonal contrasts (contrast $1=$ negative vs. neutral/positive server response; contrast 2 = neutral vs. positive server response).

All path coefficients were significant and in the predicted direction and the proposed model fit the data well for each of the distal outcome measures (Figure 3). ${ }^{4}$ Focusing on the top of Figure 3, return intentions were largely driven by negative attitudes toward the restaurant,

\footnotetext{
${ }^{4}$ All correlations significant $(p<.05)$ and in the expected direction. Correlation matrices are available from the first author.
} 
though desire for revenge toward the server was also significant. This suggests these more traditional (firm-related) outcomes may not be fundamentally “revenge seeking behaviors,” a point we consider in the general discussion. In comparison, as shown in the bottom panel of Figure 3, one noteworthy finding was that desire for revenge and attitude toward the restaurant showed approximately equal relationships with tip percentage. This suggests that tipping was based on a mix of negative attitudes toward the restaurant and revenge seeking.

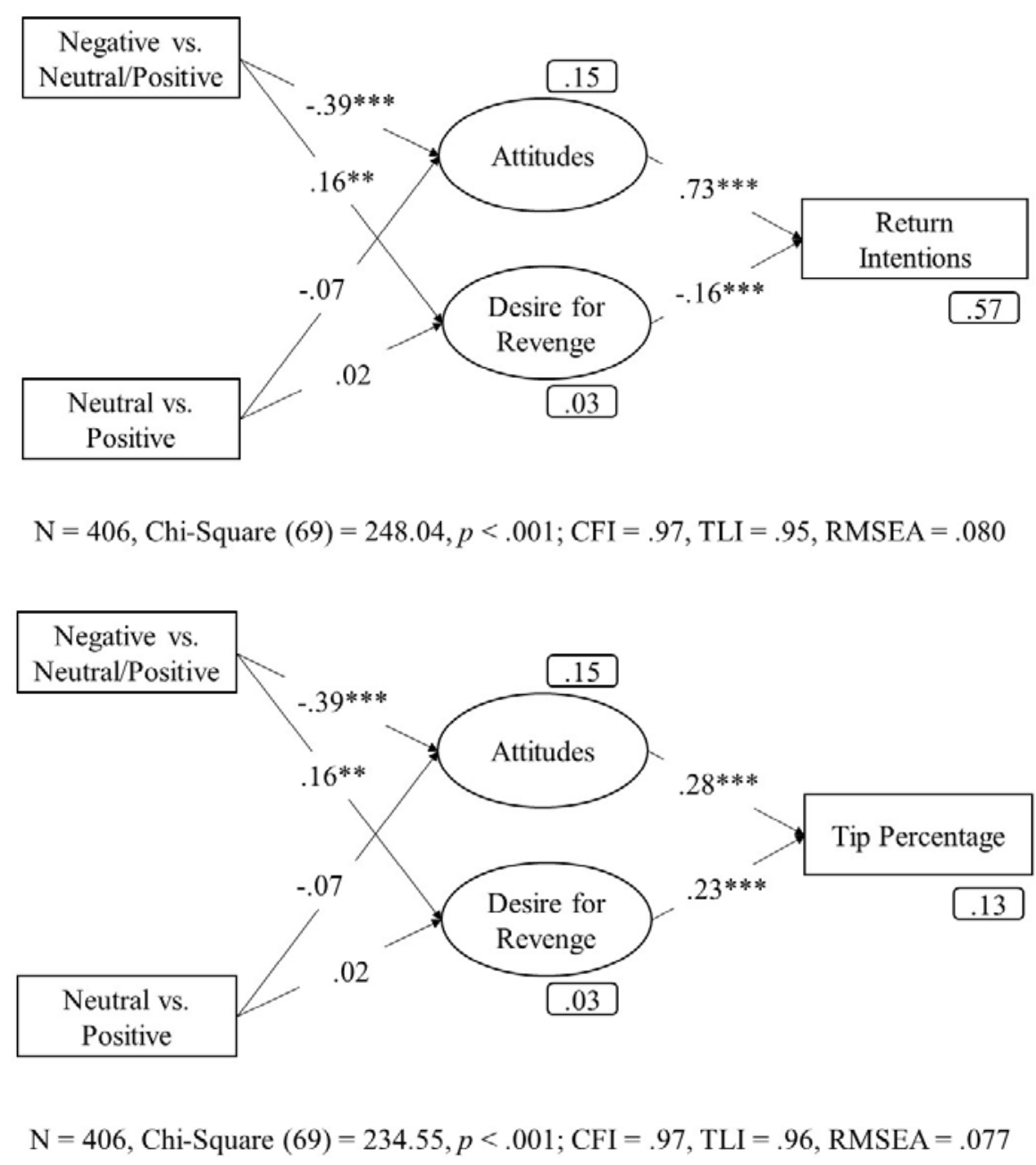

Note: Exogenous variables partition server's response into two orthogonal contrasts: (top) Negative [2] vs. Neutral/Positive [-1]; (bottom) Neutral [1] vs. Positive [-1]. Desire for revenge (toward the server) and attitude (toward the restaurant) treated as latent endogenous variables. Values in rectangles next to endogenous variables are $\mathrm{R}^{2}$ values. Standardized coefficients shown. ${ }^{* *} p<.01$; ${ }^{* * *} p<.001$

\section{Figure 3 - Path Models (Study 1)}


Witnessing Uncivil Behavior 19

\subsubsection{Process Analyses}

As a preliminary test of $\mathrm{H}_{2}$ and $\mathrm{H}_{4}$ - not including deontic injustice which was not measured in this study - we computed 95\% confidence intervals for the indirect effects implied in our model (Hayes 2018, PROCESS, Model 4, parallel mediators). Contrast 1 (negative vs. neutral/positive) was the primary focus of interest, while Contrast 2 (neutral vs. positive) was added as a covariate. Consistent with $\mathrm{H}_{2}$, a negative server response had negative indirect effect on return intentions through attitude toward the restaurant (95\% CI: -.4078, -.2633); results also revealed a smaller indirect effect through desire for revenge (95\% CI: -.0414, -.0054). Consistent with $\mathrm{H}_{4}$, a negative server response had negative indirect effect on tip percentage through desire for revenge (95\% CI: -.2339, -.0352); results also revealed an indirect effect through attitude toward the restaurant (95\% CI: -.6763, -.2240). Given that the neutral and positive response conditions yielded non-significant differences across all outcome measures, indirect effects for contrast 2 were, as expected, non-significant.

\subsection{Discussion (Study 1)}

The current study provided support for hypotheses 1-4. When third party observers overhear a service employee engage in a negative service recovery, they form negative attitudes toward the firm, a desire for revenge, and are subsequently inclined to take negative actions against both the firm and employee. Notably, positive server responses had no beneficial effect when compared to a neutral response condition. These results extend research on how customers respond when they witness uncivil behavior in a retail setting. Study 2 complemented and extended study 1 in several ways. First, to enhance the generalizability of our findings, we recruited a broader sample of consumers. Second, we incorporated perceptions of deontic injustice as a mediator linking negative server responses with negative firm attitudes and desire 
for revenge. Third, to provide practical guidance, we evaluated the efficacy of management intervention in buffering the negative effects of overheard service failures.

\section{Study 2}

\subsection{Method}

\subsubsection{Sampling and Participants Profile}

A sample of 398 U.S. residents recruited from MTurk participated in exchange for \$1 (46.7\% female; median age $=32 ; 74.9 \%$ Caucasian; detailed sample demographics shown in Web Appendix A).

\subsubsection{Scenario}

We used the scenario from study 1 . However, we compared only the negative and neutral server responses, as the positive and neutral server responses yielded identical results in study 1 . Moreover, as the high severity complaint and high severity complaint repeated yielded identical results in study 1 , we focused only on the low severity and high severity complaint conditions. Accordingly, the study used a 2 (server's response: negative vs. neutral) x 2 (complaint severity: low vs. high) x 2 (management intervention: no intervention vs. intervention) betweenparticipants design. In the management intervention condition, a manager apologized to the complaining customer, whereas in the no intervention condition, no management intervention was mentioned (Web Appendix B).

\subsubsection{Measures}

Participants next completed the six-item attitude toward the restaurant scale (Sawyer and Howard 1991; $\alpha=.96)$, rated their likelihood of returning to the restaurant ( 1 = very unlikely, 7 = very likely), completed the desire for revenge toward the server scale (Grégoire et al. 2009; $\alpha=$ .95), and indicated their tip percentage (0\%-25\%). Participants also completed a seven-item deontic injustice scale (Porath et al. 2011; $\alpha=.88$ ) (scale items in Web Appendix C). To avoid 
drawing attention to our management intervention manipulation, we conducted a separate manipulation check study, as described in the results section.

Measurement analyses again supported the discriminant and convergent validity of our scales (deontic injustice, attitude toward the restaurant, desire for revenge): Confirmatory factor analyses indicated a three-factor model fit better than a one-factor model: $\chi^{2}(3)=389.10, p<$ .001 ; the square root of the AVE for each construct $(.73, .88, .89)$ was greater than the highest correlation among the constructs (.48) (Fornell and Larcker 1981); the composite reliability of each scale exceeded $.70(.88, .95, .95)$; and each construct had an AVE greater than .50 (.53, .77, .79). Finally, the three-factor model (with the same correlated error terms estimated in study 1) fit the data well: $\chi^{2}(128)=353.25, p<.001, \mathrm{CFI}=.95$, TLI $=.95$, and RMSEA $=.066$.

\subsection{Results}

\subsubsection{Management Intervention Manipulation Check}

To check our management intervention manipulation, 60 participants from MTurk different than those in the primary study - imagined they overheard a customer at an adjacent table complain to a server over slow service and read "the server provided the complaining customer with a response.” Participants then read one of the two management interventions (Web Appendix B), and rated their impression of the management on the six-item impressions scale $(\alpha=.94)$. As expected, results indicated more favorable impressions in the intervention condition $(M=5.63)$ than in the no intervention condition $(M=4.56), t(58)=4.72, p<.001$.

\subsubsection{Server-Related Outcomes}

One goal of study 2 was to determine whether the results from study 1 would replicate using a broader sample. To ensure compatibility with study 1, we first conducted 2 (server's response: negative vs. neutral) x 2 (complaint severity: low vs. high) ANOVAs in the no intervention condition. Results revealed significant main effects of server's response on desire 
for revenge, $(F(1,199)=5.64, p<.05)$, tip percentage $(F(1,199)=3.99, p<.05)$, and deontic injustice $(F(1,199)=52.72, p<.001)$. Replicating study 1 , relative to the neutral response, the negative server response led to higher desire for revenge ( $M s=1.69$ vs. 2.07, $p<.02)$ and lower tip percentage $(M s=12.64$ vs. $11.01, p<.05$ ). Extending study 1 , the negative server response also led to higher deontic injustice than the neutral condition $(M s=4.34$ vs. $3.15, p<.001){ }^{5}$

We next tested an expanded structural equation model. All path coefficients were significant and in the expected direction, and the model fit the data well (Figure 4).

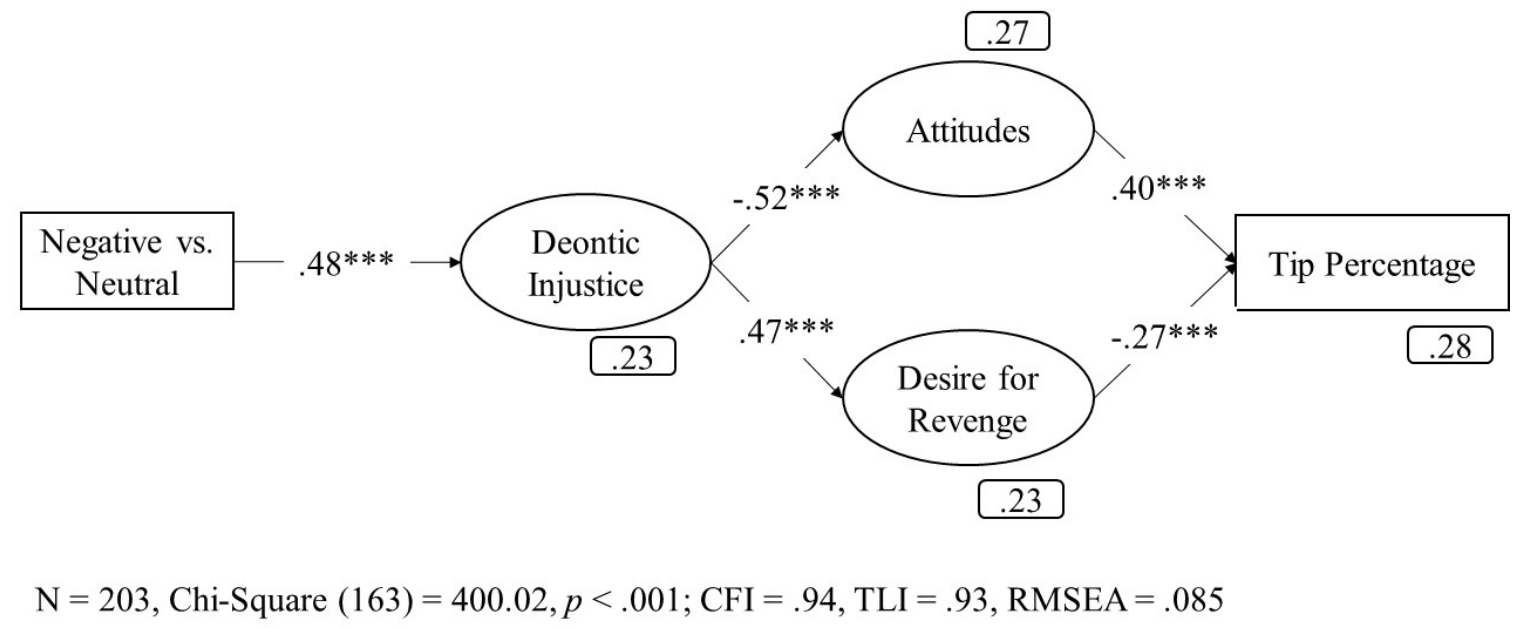

Note. Consistent with study 1 , results are from the no intervention control condition only. Path models including the management intervention condition yielded identical results. All coefficients significant $(p<$ $.001)$.

Figure 4 - Path Model for Server-Related Outcomes (Study 2)

We next used Hayes’ (2018) PROCESS program (Model 81) to test for the indirect effect of a negative server response on tip percentage through deontic injustice (first mediator)

\footnotetext{
${ }^{5}$ Results also revealed a significant main effect of customer complaint on all server-related outcomes ( $p$ values < .05), but a non-significant interaction between server's response and complaint severity ( $p$ values $>.43$ ). Results suggested that the broader sample in study 2 was more likely to cut the server slack when the customer complaint was negative. Given that this aspect of the study was mostly exploratory, we do not discuss it in detail. Readers interested in a complete summary may contact the first author.
} 
followed by attitude toward the restaurant and desire for revenge (second-stage parallel mediators). The indirect effect through desire for revenge (server's response $\rightarrow$ deontic injustice

$\rightarrow$ desire for revenge $\rightarrow$ tip percentage) was significant (95\% CI: -.8214, -.1029), supporting $\mathrm{H}_{4}$. The indirect effect through attitudes was also significant (95\% CI: -1.4363, -.3636). Thus, SEM and indirect effects tests provided good support for the model and $\mathrm{H}_{4}$.

Lastly, we conducted the complete 2 (server's response) x 2 (complaint severity) x 2 (management intervention) ANOVA on the server-related outcomes. Interestingly, results showed no main effect for management intervention ( $p$-values $>.55$ ), no two-way interaction between server response and management intervention ( $p$-values $>.28$ ), and no three-way interactions ( $p$-values $>.19$ ), indicating that the benefits of management intervention (detailed in the next section) did not extend to responses to the server.

\subsubsection{Firm-Related Outcomes}

Next, to test the buffering effect of management intervention, we conducted 2 (server's response: negative vs. neutral) x 2 (complaint severity: low vs. high) x 2 (management intervention: no intervention vs. intervention) ANOVAs on all firm-related outcomes. Supporting $\mathrm{H}_{5}$, results indicated a significant server response $\mathrm{x}$ management intervention interaction on attitude toward the restaurant $(F(1,390)=11.48, p<.001)$ and return intentions $(F(1,390)=7.19, p<.01)$, which qualified significant main effects for server's response (on attitude: $F(1,390)=13.50, p<.001$; on return intentions: $F(1,390)=7.26, p<.01)$ and management intervention (on attitude: $F(1,390)=14.02, p<.001$; on return intentions: $F(1$, $390)=8.06, p<.01$ ) (Figure 5). Replicating study 1 , in the no intervention condition, Tukey tests revealed that a negative server response reduced attitude toward the restaurant and return intentions. In comparison, in the management intervention condition, the negative server 
response no longer led to a significant reduction in attitudes or return intentions. Moreover, in the negative server response condition, attitudes and return intentions were significantly higher in the management intervention condition than in the no intervention condition.
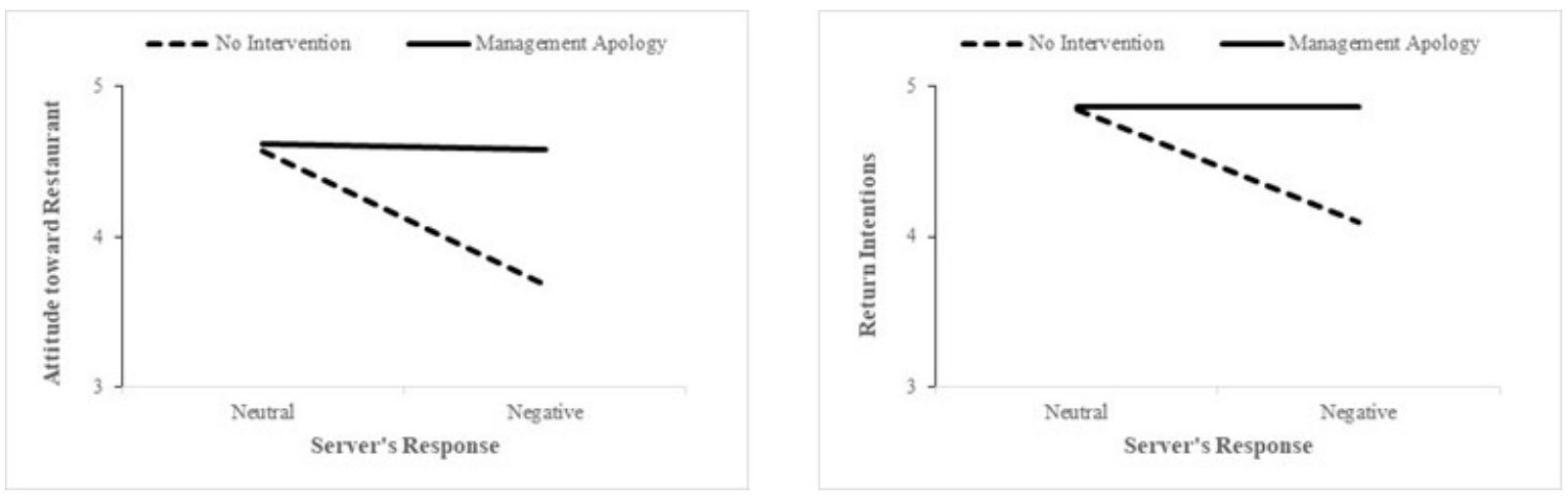

Figure 5 - Server's Response x Management Intervention on Firm Outcomes (Study 2)

Results also revealed a significant two-way interaction between server's response and management intervention on perceptions of deontic injustice $(F(1,390)=7.26, p<.01)$. Tukey tests revealed that the negative server response led to higher perceptions of deontic injustice than the neutral response in both the no intervention (4.34 vs. 3.13; mean difference $=1.21$ ) and intervention conditions (4.13 vs. 3.59; mean difference $=0.54$ ), but the magnitude of the effect in the intervention condition was weaker, suggesting a partial buffering effect.

We next used SEM to test the complete (interactive) model on return intentions (as the final outcome). Results provided good support for the model (Figure 6). 


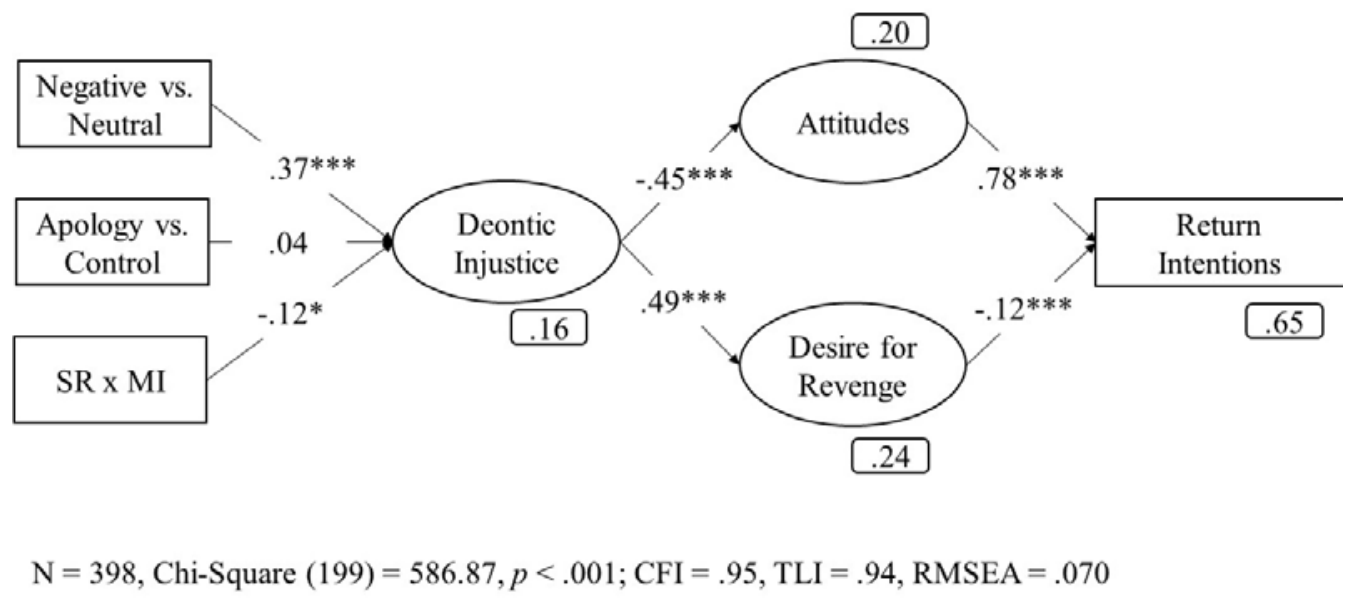

Note: Server's Response (SR): neutral = -1 , negative $=1$; Management Intervention (MI): control = -1 , apology $=1$. Values in rectangles next to endogenous variables are $\mathrm{R}^{2}$ values.

$* p<.05 ; * * * p<.001$

\section{Figure 6 - Path Model for Firm Outcomes (Study 2)}

\subsubsection{Process Analyses}

Finally, we used Hayes’ (2018) PROCESS program (customized model feature) to test for the indirect effect of the server response $\mathrm{x}$ management intervention interaction on return intentions through deontic injustice (first mediator) followed by desire for revenge and attitude toward the restaurant (second-stage parallel mediators). The indirect effect via attitudes was significant (95\% CI: .0668, .5012), supporting $\mathrm{H}_{6}$. The indirect effect through desire for revenge was not significant (95\% CI: -.0002, .0628), suggesting the indirect effect of the interaction ran through attitudes and not desire for revenge, as anticipated.

\subsection{Discussion (Study 2)}

Results in the no intervention condition replicated study 1: observers reported higher desire for revenge toward the server, lower tipping intentions, less favorable attitudes toward the restaurant and weaker return intentions. Extending study 1, management intervention fully 
buffered the adverse effect of negative server response on firm-related outcomes, yet had no effect on server-related outcomes. SEM and process analyses revealed additional support for the model as a whole, as well as $\mathrm{H}_{6}$.

\section{General Discussion}

Given their ubiquity, there has been growing interest in understanding how third party observers respond when they witness uncivil interactions among and between customers and employees. The present studies extended this emerging work by focusing on how third party observers respond when they overhear another customer's failed recovery experience. Across two experiments, results show that customers who observe servers responding negatively to another customer's complaint reduce the server's tip percentage and become less likely to return to the establishment. Process analyses suggest these effects are driven by a desire to punish the server and unfavorable attitudes toward the establishment, which are, in turn, due to perceptions of deontic injustice. Results also show that management intervention eliminates the negative consequences for the firm (but not the server). These findings offer several contributions, highlight practical insights, and open avenues for future research.

\subsection{Contributions}

The present work offers three main contributions to an understanding of how third parties respond when they overhear another customer’s service recovery process. First, we incorporated novel outcome measures that directly reflect revenge seeking (tipping). While prior research has uncovered a variety of third party reactions that suggest a desire for revenge - such as boycotting, stated desire for revenge (Porath et al. 2011), anger, and word of mouth (Mattila et al. 2014; Porath et al. 2011) - no studies have employed a direct measure of revenge seeking. Interestingly, research suggests that customers who do not complain may still reduce their 
server's tip as a way of conveying their dissatisfaction with the service they received (Voorhees et al. 2006). Extending these observations, the present results show that customers are also likely to give lower tips when they overhear their server respond negatively to an adjacent customer. These findings provide some of the most direct evidence, to date, that third party observers of failed recoveries engage in revenge seeking behavior.

Second, the present work underscores the value of management intervention for responses to the firm (but not the server). While compensation (Kwon and Jang 2012) and apologies (Joireman et al. 2013) are recognized as effective interventions in service failure settings, this finding adds subtle nuance to the effectiveness of management interventions by highlighting that they apply mainly to the way customers respond to the firm. This makes some sense, as management intervention is not designed to excuse the server's negative behavior, but rather, reestablish a global sense of trust in the firm. This leaves third party observers of service failures free to punish the norm violator (server).

Finally, the present work utilized structural equation modeling and indirect effects testing to evaluate the model at a global and local level. While testing indirect effects yields insights into underlying mechanisms, there is value in testing broader models incorporating a broader range of processes (Bagozzi and Yi 2012; Iacobucci 2009). With that said, future research could explore additional avenues through which the process of overheard service failures unfolds.

\subsection{Practical Implications}

The present work also offers several practical implications relevant to the hospitality industry. First, an employee’s negative response to a service failure can have personal ramifications beyond the server's interaction with a disgruntled customer. This may seem intuitive. However, it bears repeating that while some research has examined how third party 
observers perceive failed recoveries and subsequently respond to the firm, no studies have directly examined how third party observers respond to frontline employees. The present studies reveal that, in the absence of any management intervention, negative server responses led third party observers to experience an increase in desire for revenge against the server and offer the server lower tips. To gain additional insight into the implications of these results, we compared stated tip percentage in our studies with respondents’ usual tip percentage in real-world settings. Overall, respondents reported significantly lower tips in our studies compared to their usual tips (-3.6\%). More importantly, the reduction in tips was significantly larger in the negative server response condition (-5.1\%) than in the neutral $(-2.4 \%)$ or positive server response conditions (1.9\%), which did not differ (Figure 7). While these comparisons should be interpreted with caution, they do yield some insight into the practical implications of the present findings.

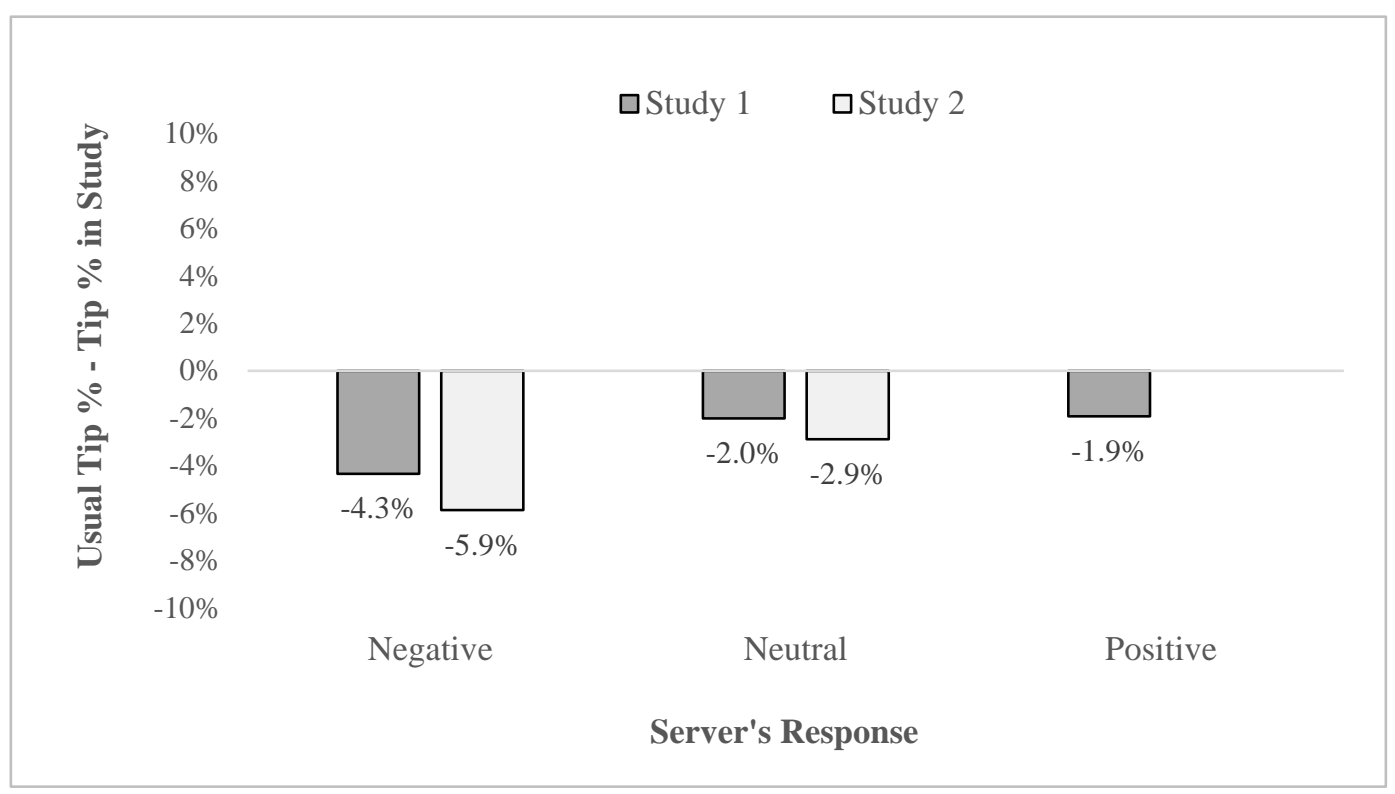

Note. Each mean significantly below $0(p<.01)$, indicating tip percentages were lower than usual tip percentage. One-way ANOVAs with follow-up Tukey tests revealed that reduction in tip percentage was significantly larger in the negative response condition than in the neutral and positive response conditions, respectively $(p<.05)$. To ensure comparability with study 1 , results in study 2 are from the no intervention control condition. The positive server response condition was not used in study 2.

\section{Figure 7 - Reduction in Usual Tip Percentage as a Function of Server's Response}


The failure of management intervention to eliminate these negative server-related outcomes should sound an additional warning for servers involved in failed recoveries: management intervention may salvage responses toward the firm, but such interventions do not appear to protect against observers' tendency to punish the server. Tellingly, study 1 results suggest service employees need not "bend over backwards" to please customers, as observers do not differentiate between neutral and positive server responses to customer complaints. Considering the emotional labor involved in service settings, overly positive responses may also lead to employee exhaustion and further declines in performance (e.g., Yoo and Arnold 2016).

Results from study 2 also hold clear implications for hospitality managers. When a failed recovery is underway, a simple apology from management to the complaining customer can eliminate observers' reduced tendency to return to the establishment. Process analyses suggest this full buffering effect occurs because management intervention reduces perceptions of deontic injustice which subsequently leads to more favorable attitudes toward the firm.

\section{4. $\quad$ Limitations and Future Research}

While the present work contributes to work on overheard service failures, three limitations deserve mention. First, we used hypothetical scenarios. Although common and justified in hospitality and service failure literatures (e.g., Bitner 1990; Wang, Miao, and Mattila 2015; Weber, Sparks, and Hsu 2016), future research should utilize more naturalistic settings (e.g., Lee, Noble, and Biswas 2017). Second, our samples included students and respondents on MTurk who were compensated for their participation. Use of more representative respondent samples who are not compensated would increase confidence in the generalizability of the results. Finally, while our results provide insight into processes underlying this phenomenon, and one possible solution to this problem, much remains to be learned. In particular, future research 
identifying boundary conditions (e.g., gender of the server; Bharadwaja, Lee, and Madera 2018) and additional mechanisms (e.g., embarrassment; Wu, and Mattila 2013) would further advance an understanding of how customers respond when they witness a variety of uncivil behaviors. 


\section{References}

Bagozzi, Richard P. and Youjae Yi (2012), "Specification, Evaluation, and Interpretation of Structural Equation Models," Journal of the Academy of Marketing Science, 40 (January), 834.

Bechwati, Nada N. and Maureen Morrin (2003), “Outraged Consumers: Getting Even at the Expense of Getting a Good Deal,” Journal of Consumer Psychology, 13 (4), 440-453.

Bell, Chip R. and Ron. E. Zemke (1987), “Service Breakdown: The Road to Recovery,” Management Review, 76 (10), 32-5.

Bharadwaja, Shina, Lindsey Lee, and Juan M. Madera (2018), “Customer Evaluations of Service-Oriented Citizenship Behaviors: Agentic and Communal Differences,” International Journal of Hospitality Management, 70, 120-9.

Bitner, Mary J. (1990), "Evaluating Service Encounters: The Effects of Physical Surroundings and Employee Responses," Journal of Marketing, 54 (April) 69-82.

Bitner, Mary J., Bernard H. Booms, and Mary S. Tetreault (1990), “The Service Encounter: Diagnosing Favorable and Unfavorable Incidents,” Journal of Marketing, 54 (January), 7184.

Bolton, Lisa E. and Anna S. Mattila (2015), "How Does Corporate Social Responsibility Affect Consumer Response to Service Failure in Buyer-Seller Relationships?" Journal of Retailing, 91 (March), 140-53.

Casidy, Riza and Hyunju Shin (2015), “The Effects of Harm Directions and Service Recovery Strategies on Customer Forgiveness and Negative Word-of-Mouth Intentions,” Journal of Retailing and Consumer Services, 27, 103-12. 
Chang, Kuo-Chien (2016), “Effect of Servicescape on Customer Behavioral Intentions:

Moderating Roles of Service Climate and Employee Engagement," International Journal of Hospitality Management, 53, 116-128.

Fehr, Ernst and Urs Fischbacher (2004), “Third-Party Punishment and Social Norms,” Evolution and Human Behavior, 25 (March), 63-87.

Fornell, Claes and David F. Larcker (1981), "Evaluating Structural Equation Models with Unobservable Variables and Measurement Error," Journal of Marketing Research, 18 (February), 39-50.

Grégoire, Yany, Thomas M. Tripp, and Renaud Legoux (2009), "When Customer Love Turns into Lasting Hate: The Effects of Relationship Strength and Time on Customer Revenge and Avoidance," Journal of Marketing, 73 (November), 18-32.

Hanks, Lydia and Nathaniel D. Line (2018), “The Restaurant Social Servicescape: Establishing a Nomological Framework,” International Journal of Hospitality Management, 74, 13-21. Hayes, Andrew F. (2018), Introduction to Mediation, Moderation, and Conditional Process Analysis: A Regression-Based Approach, $2^{\text {nd }}$ ed. New York: Guilford Press.

Henkel, Alexander P., Johannes Boegershausen, Anat Rafaeli, and Jos Lemmink (2017), “The Social Dimension of Service Interactions: Observer Reactions to Customer Incivility,” Journal of Service Research, 20 (May), 120-34.

Iacobucci, Dawn (2009), "Everything You Always Wanted to Know About SEM (Structural Equations Modeling) But Were Afraid to Ask," Journal of Consumer Psychology, 19 (October), 673-80. 
Joireman, Jeff, Yany Grégoire, Berna Devezer, and Thomas M. Tripp (2013), "When Do Customers Offer Firms a 'Second Chance’ Following a Double Deviation? The Impact of Inferred Firm Motives on Customer Revenge and Reconciliation," Journal of Retailing, 89 (September), 315-37.

Kähr, Andrea, Bettina Nyffenegger, Harley Krohmer and Wayne D. Hoyer (2016), "When Hostile Consumers Wreak Havoc on Your Brand: The Phenomenon of Consumer Brand Sabotage," Journal of Marketing, 80 (May), 25-41.

Keiningham, Timothy L., Forrest V. Morgeson III, Lerzan Aksoy, and Luke Williams (2014), "Service Failure Severity, Customer Satisfaction, and Market Share: An Examination of the Airline Industry,” Journal of Service Research, 17 (November), 415-31.

Kwon, SoYoen and SooCheong (Shawn) Jang (2012), "Effects of Compensation for Service Recovery: From the Equity Theory Perspective,” International Journal of Hospitality Management, 31, 1235-43.

Lee, Na Young, Stephanie M. Noble, and Dipayan Biswas (2017), "Hey Big Spender! A Golden (Color) Atmospheric Effect on Tipping Behavior," Journal of the Academy of Marketing Science, 46 (2), 317-37.

Lin, Lily, Darren W. Dahl, and Jennifer J. Argo (2013), "Do the Crime, Always Do the Time? Insights into Consumer-to-Consumer Punishment Decisions," Journal of Consumer Research, 40 (June), 64-77.

Lynn, Michael and Michael McCall (2000), "Gratitude and Gratuity: A Meta-Analysis of Research on the Service-Tipping Relationship," Journal of Socio-Economics, 29 (December), 203-14. 
Mattila, Anna, Lydia Hanks, and Chenya Wang (2014), “Others Service Experiences: Emotions, Perceived Justice, and Behavior,” European Journal of Marketing, 48 (April), 552-71.

McColl-Kennedy, R. Janet, Paul G. Patterson, Amy K. Smith and Michael K. Brady (2009), “Customer Rage Episodes: Emotions, Expressions, and Behaviors,” Journal of Retailing, 85 (June), 222-37.

McCollough, Michael A., Leonard L. Berry, and Manjit S. Yadav (2000), “An Empirical Investigation of Customer Satisfaction after Service Failure and Recovery,” Journal of Service Research, 3 (November), 121-37.

Melián-González, Santiago and Jacques Bulchand-Gidumal (2017), “Extending the Scope of Hotel Client Reactions to Employee Injustice: Hotel Employer Reviews on the Internet,” International Journal of Hospitality Management, 63, 93-100.

Miao, Li (2014), "Self-Regulation and "Other Consumers" at Service Encounters: A Sociometer Perspective," International Journal of Hospitality Management, 39, 122-9.

Miao, Li, Anna S. Mattila, and Dan Mount (2011), “Other Consumers in Service Encounters: A Script Theoretical Perspective,” International Journal of Hospitality Management, 30, 93341.

Porath, Christine, Debbie MacInnis, and Valerie Folkes (2010), "Witnessing Incivility among Employees: Effects on Consumer Anger and Negative Inferences about Companies,” Journal of Consumer Research, 37 (August), 292-303.

Porath, Christine, Debbie MacInnis, and Valerie Folkes (2011), “It’s Unfair: Why Customers Who Merely Observe an Uncivil Employee Abandon the Company,” Journal of Service Research, 14 (August), 302-17. 
Richins, Marsha L. (1983), "Negative Word-Of-Mouth by Dissatisfied Consumers: A Pilot Study," Journal of Marketing, 47 (January), 68-78.

Sawyer, Alan G. and Daniel J. Howard (1991), "Effects of Omitting Conclusions in Advertisements to Involved and Uninvolved Audiences," Journal of Marketing Research, 28 (November), 467-74.

Singh, Jagdip (1990), "A Typology of Consumer Dissatisfaction Response Styles," Journal of Retailing, 66 (March), 57-100.

Skarlicki, Daniel P., Jane O’Reilly, and Carol T. Kulik (2015), “The Third Party Perspective on (In)justice," in Oxford Handbook of Justice in the Workplace, Russell Cropanzano and Maureen L. Ambrose, eds. Oxford: Oxford University Press, 235-55.

Smith, Amy K. and Ruth N. Bolton (1998), "An Experimental Investigation of Customer Reactions to Service Failure and Recovery Encounters," Journal of Service Research, 1 (August), 65-81.

Smith, Amy K., Ruth N. Bolton, and Janet Wagner (1999), "A Model of Customer Satisfaction with Service Encounters Involving Failure and Recovery," Journal of Marketing Research, 36 (August), 356-72.

Sobel, Michael E. (1982), "Asymptotic Confidence Intervals for Indirect Effects in Structural Equation Models," Sociological Methodology, 13, 290-312.

Tax, Stephen S., Stephen W. Brown, and Murali Chandrashekaran (1999), “Customer Evaluations of Service Complaint Experiences: Implications for Relationship Marketing,” Journal of Marketing, 62 (4), 60-77.

Tombs, Alastair and Janet R. McColl-Kennedy (2003), "Social-Servicescape Conceptual Model," Marketing Theory, 3 (4), 447-75. 
Van Vaerenbergh, Yves, Iris Vermeir, and Bart Larivière (2013), “Service Recovery’s Impact on Customers Next-in-Line,” Managing Service Quality, 23 (November), 495-512.

Voorhees, Clay M., Michael K. Brady, and David M. Horowitz (2006), “A Voice from the Silent Masses: An Exploratory and Comparative Analysis of Noncomplainers,” Journal of the Academy of Marketing Science, 34 (October), 514-27.

Wan, Lisa C., Elisa K. Y. Chan, and Lei Su (2011), "When Will Customers Care about Service Failures That Happened to Strangers? The Role of Personal Similarity and Regulatory Focus and its Implication on Service Evaluation,” International Journal of Hospitality Management, 30 (March), 213-20.

Wang, Chen-Ya, Li Miao, and Anna S. Mattila (2015), “Customer Responses to Intercultural Communication Accommodation Strategies in Hospitality Service Encounters,” International Journal of Hospitality Management, 51, 96-104.

Weber, Karin, Beverley Sparks, and Cathy H. C. Hsu (2016), “The Effects of Acculturation, Social Distinctiveness, and Social Presence in a Service Failures Situation,” International Journal of Hospitality Management, 56, 44-55.

Wirtz, Jochen and Anna S. Mattila (2004), “Consumer Responses to Compensation, Speed of Recovery and Apology after a Service Failure,” International Journal of Service Industry Management, 15 (April), 150-66.

Wu, Luorong (Laurie) and Anna Mattila (2013), “Investigating Consumer Embarrassment in Service Interactions,” International Journal of Hospitality Management, 33, 196-202. Yoo, Jaewon and Todd J. Arnold (2016), “Frontline Employee Customer-Oriented Attitude in the Presence of Job Demands and Resources: The Influence Upon Deep and Surface Acting,” Journal of Service Research, 19 (February), 102-17. 